\title{
Practical Implementation of Contract Administration Performance Model in Qatar Construction Projects
}

\author{
Murat Gunduz \\ mgunduz@qu.edu.qa \\ Department of Civil and Architectural Engineering, Qatar University, Doha, Qatar
}

Hesham A. Elsherbeny

he1512830@student.qu.edu.qa

Engineering Management Program, College of Engineering, Qatar University, Doha, Qatar

\begin{abstract}
Globally, the performance of Construction Contract Administration (CCA) is becoming of significant interest as the industry suffers from notable delays, cost overruns, and disputes as a consequence of poor contract administration practices. In Qatar, the pace of projects will continue after hosting the FIFA 2022 World Cup to achieve the 2030 Qatar National Vision and beyond, therefore, monitoring of the proper CCA implementation and performance is necessary. Due to the wide scope and complicated nature of CCA, there is yet no consensus on how to assess its performance. This study briefly presents a systematic, operational, and multi-dimensional construction Contract Administration Performance Framework (CAPF) consisting of 93 CCA key measures/ tasks categorized in 11 CCA dimensions/process groups. The proposed framework is validated by structural equation modeling and subsequently, the Contract Administration Performance Model (CAPM) model was established. Through this study, the CAPM and its components are briefly explained, and then implemented on a real-world sample of 13 small, medium, and major construction projects in Qatar covering both public and private sectors, and then the performance is benchmarked. It is found that the model provides an operational basis for measuring the CCA Group Performance Indices (GPI), the overall Construction Contract Administration Performance Index (CCAPI) and support the identification of underperforming groups. The benchmarking value for the CCAPI $(77.5 \%)$ demonstrates that the level of CCA performance is good. Also, the benchmarking values of GPI (range $74.3 \%$ to $87.8 \%$ ) are good, except risk management ( $\mathrm{GPI}=50.5 \%)$, which needs an improvement program.
\end{abstract}

Keywords: Optimized aggregate gradation; Portland-limestone cement; Cementitious content; Concrete pavement; 3D FEM model

\section{INTRODUCTION}

According to Jarkas and Mubarak (2016), poor contract administration that reduces liquidity in the markets and employer changes are currently the main causes of disputes. Also, failure to administer, understand, and comply with the contract properly leads to making the dispute difficult (Harris 2013). Furthermore, Arcadis (2017) presents poor contract administration as time-consuming and as the main source of disputes in the Middle East, Europe, Asia, and North America. In 2015, the average global value of disputes was US\$46 million, and the average length was 15.5 months versus US\$82 
million and 15.2 months in the Middle East. In 2016, the average global value of disputes was dropped to US $\$ 42.8$ million, and the average length was 14 months versus US\$56 million and 13.7 months in the Middle East. What's more, several authors study the consequences of poor contract administration and inefficient management of contracts. The consequences are listed as working against sustaining the industry; heavy fine for non-compliance; substantial loss of savings; incur resources waste; delay in time; productive loss; several non-value added activities; poor control of operations; low rate of satisfying customers; unwanted costs; and more risks (Awwad et al., 2016). The importance of contract administration and the consequences of the poor administration in construction projects necessitate an additional urgency to investigate the contract administration process performance and identify the elements that reflect the good contract administration practice. Also, challenges associated with the industry necessitate the need for effective management and proper administration of the contract (Gitonga et al., 2017) and establish an efficient and effective process to maintain a strong relationship between the parties (Bin Zakaria et al., 2013).

\section{QATAR CONSTRUCTION}

In Qatar, the workload continues to focus on arrangements for the FIFA World Cup 2022 and the related infrastructure projects (AECOM 2016). As a result, several capital investments are being funded, and the construction industry continues to stay as a key element of the nation's plan. Qatar shall continue to invest around $\$ 220$ billion in capital projects and infrastructure over the next few years. The construction is regarded as one of the largest industries in Qatar; the sector shared 14.5, 15.6 and 17.5\% percent of real Gross Domestic Product (GDP) in 2014, 2015 and 2017, respectively, and is still the main contributor to economic growth during the coming years. The construction output is increased from QR 52.5 to 88 Billion for the period between 2014 to 2017, with the highest sectorial growth in the economy by (14.5\%) and falls far behind the manufacturing sector with an average annual growth of only $2.6 \%$ (Authority 2018). In 2018, the construction sector has contributed to $1.8 \%$ of the total expected growth of $2.6 \%$. With an expected growth rate of $5.2 \%$, the construction will contribute to at least $50 \%$ of this growth rate between 2018 to 2020 . Not only this but construction activities intensively employs around $41 \%$ of the total labor force due to the construction boom and speed up large-scale/mega infrastructure projects for the FIFA 2022 session (Statistics 2016, Authority 2018). While the government is committed to allocating $40 \%$ of its budget to infrastructure projects, the workload continues to focus on arrangements of sports facilities and the related projects (AECOM 2016).

\section{CONTRACT ADMINISTRATION PERFORMANCE MODEL}

Gunduz and Elsherbeny (2019) established a systematic, operational, and multi-dimensional construction Contract Administration Performance Framework (CAPF). The framework with detailed measures was developed, investigated, and tested by involving a three-step research design. At the first step, 82 measures under 11 dimensions were determined by literature review, interviews with four construction professionals. In the second step, two rounds modified Delphi study was conducted with 17 construction experts, additional 13 measures were identified, and the collected data were analyzed 
for expert's consensuses by employing Spearman rank-order correlation, mode score, mode value, and standard deviation to mean ratio (SDMR). In the third step, the strength of agreement was measured by inter-rater agreement (IRA) analysis, and the agreement level represents $94.6 \%$ of the proposed key factors and $100 \%$ of the proposed groups. Consequently, a significant consensus was achieved, and construction experts recognized the importance of the identified key factors on the overall performance of the project. At the last step, the model was externally validated through two pilot projects and the results confirmed the generalizability and measurability of the proposed framework for any construction project.

The proposed framework was based on (1) comprehensive literature review on construction contract administrator roles and responsibilities; (2) key success factors for contract administration and management; (3) the obligations of the CCA team under the different forms of contract such as Qatar general conditions of contract: GCC 1987, International Federation of Consulting Engineers (FIDIC): Red Book 1999, American Institute of Architects (AIA): A201-2007, Joint Contracts Tribunal : JCT 2011, and New Engineering Contract NEC:2005; (4) obligations of the contract administration team under professional service agreements to include Qatar professional service agreement : PSA 2010 (PWA 2010), and FIDIC White Book 2017; (5) contract administration previous models; and (6) strategies to avoid poor construction contract administration. The proposed framework contained 11 project management process groups and 93 key tasks (measures) affecting the construction contract administration performance as shown in Appendix A.

An on-line questionnaire was distributed to around 1000 practitioners to rate the importance of the CCA measures and process groups, and 336 completed questionnaires were used in data analysis using structural equation modeling. The model achieved the goodness of fit, reliability, validity requirements, as shown in Figure 1. The GPI and CCAPI were calculated from the standardized factor loading- as weighted scores - by the methodology proposed by (Gunduz et al., 2018). As a result, the within-group measures weights are shown in appendix A. The CCAPI index is calculated through Equation 1 where $P i$ represents summations of measures performance within each individual group.

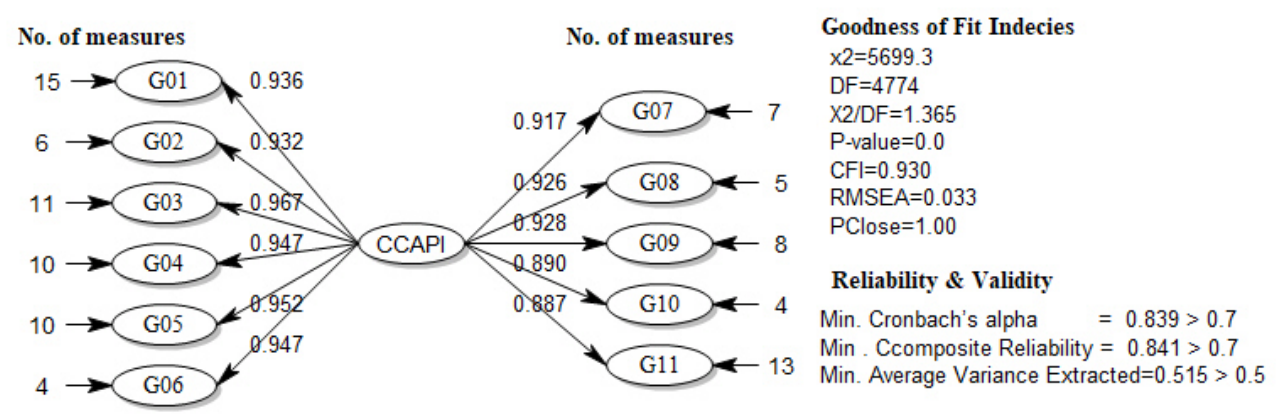

Figure 1: CAPM Second-Order SEM Model

$C C A P I=\left[9.15 P_{1}+9.11 P_{2}+9.45 P_{3}+9.26 P_{4}+9.31 P_{5}+9.26 P_{6}+\right.$ $\left.8.96 P_{7}+9.05 P_{8}+9.07 P_{9}+8.7 P_{10}+8.67 P_{l 1}\right] / 100$ 


\section{RESEARCH METHODOLOGY}

The study adopted an actual "case studies" research approach. 13 small to major construction projects covering both public and private sectors and different project types are selected. CCA experts completed performance assessment forms and then incorporated data into the CAPM model to calculate the CCA performance for the process groups and the overall project as well. The performance level was benchmarked at the project level and group performance level. Finally, the results have been discussed, and the conclusion is drawn.

\section{MODEL IMPLEMENTATION}

\subsection{Profile of Projects}

The CAPM was employed to assess the CCA performance in 13 construction projects. The assessment forms were completed by the CCA experts (minimum 15 years of experience in contract administration) according to a scale between 0 to 100 . Where the variables were not implemented, the assessment was recorded as blank, and their relative weights were redistributed to the other measures within the same group. Out of 13 projects, 6 projects were public, and the other 7 projects were private projects. 10 projects represented building type construction (i.e., mega administration building, educational and health facilities, malls and markets, tower, villa compounds, and apartment buildings, drainage, and industrial facilities) and the values of construction ranged between 1000 to USD4million. 3 projects were completed, 3 projects passed testing on completion, and the remaining 7 projects were under construction. Table 1. shows the profile of the 13 projects.

Table 1: Profile of Projects 1 To 13

\begin{tabular}{|c|c|c|c|}
\hline Project & Sector & Type & Project Value (US Million) \\
\hline$\# 1$ & Public & Building & 490 \\
\hline$\# 2$ & Public & Building & 232 \\
\hline$\# 3$ & Public & Building & 100 \\
\hline$\# 4$ & Public & Infrastructure & 60 \\
\hline$\# 5$ & Public & Industrial facilities & 38 \\
\hline$\# 6$ & Private & Building & 14 \\
\hline$\# 7$ & Private & Building & 1000 \\
\hline$\# 8$ & Private & Building & 92 \\
\hline$\# 9$ & Private & Building & 75 \\
\hline$\# 10$ & Private & Building & 32 \\
\hline$\# 11$ & Private & Building & 28 \\
\hline$\# 12$ & Private & Building & 15 \\
\hline$\# 13$ & Private & Infrastructure & 4 \\
\hline
\end{tabular}

\subsection{Results of Model Implementation}

The results of the construction contract administration performance index (CCAPI) 
of the 13 projects and the Group Performance Index (GPI) for the 11 groups are presented in Table 2. The CCAPI for project \#1 is calculated as $87.0 \%$. The results obtained by calculating the performance level of each process group are quite revealing that the best performance is related to G04-Quality \& Acceptance (GPI=95\%) while the worst implemented process group is G10-Contract Risk Management (GPI= 55\%). Except for the risk management, no significant differences are observed between the different GPIs. For project \#2, CCAPI is calculated as $67.4 \%$. The best performance is related to G01-Project governance and start-up ( $\mathrm{GPI}=93.9 \%)$, while the worst performance is related to G10-Contract Risk Management (GPI= 58.3\%). Except for the first group, no significant differences between the different groups are identified. For project \#3, CCAPI is calculated as $77.0 \%$ and the best performances are related to G09-Claims \& Disputes Resolution and G03-Communication \& Relationship with GPIs of $86.1 \%$ and $85.3 \%$, respectively. On the contrary, the worst groups are G10-Contract Risk Management and G01-Project Governance \& Start-up with GPIs of $65.0 \%$, and $67 \%$, respectively. Minor significant differences between groups are observed. For project \#4, CCAPI is calculated as $92.5 \%$. The best groups are G05-Monitoring \& Reporting, G07-Financial Management, G08-Changes \& Changes Control, and G10-Contract Risk Management with ultimate GPIs of $100 \%$. The lowest group is G04-Quality \& Acceptance (GPI=78.5\%). For project \#5, CCAPI is calculated as $87.1 \%$ and the best groups are G05-Monitoring \& Reporting, G06-Document \& Record, and G08-Changes \& Changes Control with ultimate GPIs of $100 \%$. The lowest groups are G03-Communication \& Relationship, G04-Quality \& Acceptance, and G10-Contract Risk Management with GPIs of range 75.5 to $72.0 \%$.

In the private sector, The CCAPI for project \#6 is calculated as $79.7 \%$. The best group is G08-Changes \& Changes Control (GPI $=100 \%$ ). The lowest implemented process groups are G10-Contract Risk management and G06-Document \& Record with GPIs of zero, and $72.1 \%$, respectively. For project \#7, CCAPI is calculated as $86.6 \%$, and the best groups are G06-Document \& Record, and G07-Financial Management, with $100 \%$ GPIs while the lowest implemented process group is G02-CA Team Management, with GPI of $70.4 \%$. For project \#8, CCAPI is calculated as $80.6 \%$, and the best groups are G08-Changes \& Changes Control, and G09-Claims \& Disputes Resolution with $100 \%$ ultimate performance. The lowest implemented process group is G10-Contract Risk Management with GPI of zero and then G11-Contract Close-Out, with only $43.4 \%$ performance level. For project \#9, CCAPI is calculated as $64.0 \%$. The best groups are G08-Changes \& Changes Control and G09-Claims \& Disputes Resolution with 85.3\% GPIs. The lowest implemented group is G10-Contract Risk Management with only GPIs of $38.9 \%$ performance. For project \#10, CCAPI is calculated as $73.6 \%$, and the best group is G09-Claims \& Disputes Resolution with GPI of $87.5 \%$ and then is followed by G07-Financial Management with GPIs of $87.3 \%$. The lowest implemented group is G10-Contract Risk Management, with only $57.2 \%$ performance level. For project \#11, CCAPI is calculated as $59.6 \%$. The best-implemented groups are G01-Project Governance \& Start-up, G02-CA Team Management, and G09-Claims \& Disputes Resolution (GPIs $=6.9$ to $75 \%$ ). The lowest group is G10-Contract Risk Management, with only $38.9 \%$ GPI. The CCAPI for project $\# 12$ is calculated as $67.1 \%$. The best- group is G06-Document \& Record with (GPI= 82.5\%) and then followed by the G08-Changes \& 
Changes Control (GPI= 81.0\%). The lowest group is G10-Contract Risk Management, with only $57.6 \%$ performance level. Finally, the CCAPI for project \#13 is calculated as $84.7 \%$. The best groups are G07-Financial Management, G08-Changes \& Changes Control, and G09-Claims \& Disputes Resolution with an ultimate GPI of $100 \%$. The lowest groups are G05-Monitoring \& Reporting and G06-Document \& Record (GPIs=61.1\% and $63.0 \%$, respectively).

Table 2: Calculated GPI and CCAPI for Projects 1 to 13

\begin{tabular}{|c|c|c|c|c|c|c|c|c|c|c|c|c|c|c|}
\hline \multirow{2}{*}{ Group } & \multicolumn{10}{|c|}{ Project } \\
\cline { 2 - 15 } & $\mathbf{\# 1}$ & $\mathbf{\# 2}$ & $\mathbf{\# 3}$ & $\mathbf{\# 4}$ & $\mathbf{\# 5}$ & $\mathbf{\# 6}$ & $\mathbf{\# 7}$ & $\mathbf{\# 8}$ & $\mathbf{\# 9}$ & $\mathbf{\# 1 0}$ & $\mathbf{\# 1 1}$ & $\mathbf{\# 1 2}$ & $\mathbf{\# 1 3}$ & $\mathbf{A v g}$ \\
\hline G01 & 86.8 & 93.9 & 68.0 & 90.1 & 86.4 & 82.3 & 94.3 & 84.5 & 79.6 & 73.2 & 76.9 & 51.4 & 92.1 & 81.5 \\
\hline G02 & 82.0 & 67.3 & 73.8 & 91.3 & 89.9 & 84.2 & 70.4 & 84.2 & 43.9 & 74.2 & 76.3 & 63.4 & 86.9 & 76.0 \\
\hline G03 & 92.3 & 62.3 & 85.3 & 79.9 & 75.5 & 97.5 & 91.0 & 97.7 & 71.2 & 61.2 & 56.9 & 71.1 & 73.4 & 78.1 \\
\hline G04 & 95.0 & 67.2 & 82.7 & 78.5 & 75.5 & 76.4 & 88.4 & 88.1 & 59.1 & 61.2 & 45.5 & 65.5 & 82.7 & 74.3 \\
\hline G05 & 92.6 & 58.5 & 80.2 & 100.0 & 100.0 & 86.2 & 79.2 & 91.1 & 64.4 & 70.9 & 39.6 & 63.4 & 61.0 & 75.9 \\
\hline G06 & 92.5 & 69.9 & 81.3 & 94.0 & 100.0 & 72.1 & 100.0 & 96.1 & 61.3 & 86.1 & 52.6 & 82.5 & 63.0 & 80.9 \\
\hline G07 & 91.0 & 61.1 & 78.9 & 100.0 & 85.8 & 97.4 & 100.0 & 95.6 & 54.2 & 87.3 & 65.3 & 63.0 & 100.0 & 83.1 \\
\hline G08 & 92.0 & 64.9 & 78.1 & 100.0 & 100.0 & 100.0 & 93.9 & 100.0 & 85.3 & 79.7 & 66.6 & 81.0 & 100.0 & 87.8 \\
\hline G09 & 90.0 & 70.2 & 86.1 & & 87.6 & 86.5 & 87.9 & 100.0 & 80.5 & 87.5 & 75.0 & 74.5 & 100.0 & 85.5 \\
\hline G10 & 55.0 & 58.3 & 65.0 & 100.0 & 72.0 & 0.0 & 63.6 & 0.0 & 38.9 & 57.2 & 38.9 & 57.6 & & 50.5 \\
\hline G11 & 86.5 & & 67.8 & & 85.1 & 91.3 & 83.0 & 43.4 & & 71.3 & 61.6 & 64.3 & 90.4 & 74.5 \\
\hline $\begin{array}{c}\text { CCA- } \\
\text { PI }\end{array}$ & 87.0 & 67.4 & 77.1 & 92.5 & 87.1 & 79.7 & 86.6 & 80.6 & 64.0 & 73.6 & 59.6 & 67.1 & 84.7 & 77.5 \\
\hline \multicolumn{19}{|c|}{ CCAPI Public= 82.4} & \multicolumn{10}{|c|}{ CCAPI Private $=74.5$} & & \\
\hline
\end{tabular}

\subsection{Discussion of Results}

The performance scale is set to a 4-point scale (i.e., excellent performance $>=90$; good performance 70-89; average performance 50-69; needs improvement/ poor performance 0-49). This scale is adopted by several architects and engineering consultants in Qatar to reflect their performance level. At the project level, the CCAPI benchmarking value for the 13 projects is found to be $77.5 \%$, as shown in Figure 2. The result shows that the highest calculated CCAPI for project \#4 is $92.5 \%$, while the lowest calculated CCAPI is $59.6 \%$ for project \#11. The overall CCAPI values for projects \#1, 3 to 8 , and 13 exceed the benchmarking value. The CCAPI of project\# 10 is slightly dropped below the benchmarked value, while CCAPI of projects \#2, 12, 9, and 11 are significantly away from the benchmarking value. Therefore, the management of the last-mentioned projects should focus on improving the performance of the individual process groups to enhance the overall performance. Also, the significant differences among projects necessitate the need to identify the performance of the project team across different groups. It is worthy to note that the CCAPI of public sectors $(82.4 \%)$ is higher than the private sector $(74.5 \%)$. This is referred to as the legalization and constraints of rules in the public sector (Patajoki 2013). Following the performance rating scale, it could be concluded that the overall performance of the investigated projects ranged from average to excellent. 


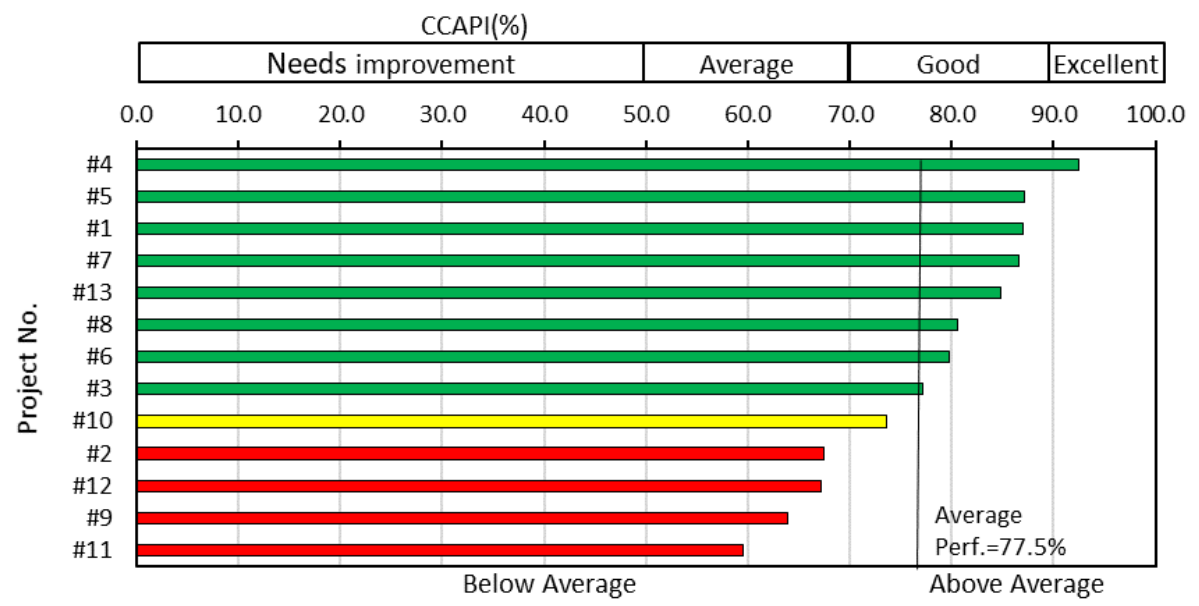

Figure 2: Calculated CCAPI for projects \# 1 to 13

At the process group level, as shown in Figure 3, it is worth noting that 5 groups, namely: G01, G03, G06, and G07 to G09 demonstrate average (GPI) higher than the benchmarking value. On the contrary, G08-Changes \& Changes Control represents the highest performance (GPI=87.8\%) and is followed by G09-Claims \& Disputes Resolution $(\mathrm{GPI}=85.5 \%)$. On the negative side, 3 groups (G02-Contract Administration Team Management, G04-Quality \& Acceptance, and G05-Performance Monitoring \& Reporting) are slightly below the benchmarking value but within a range of 5\%. G10-Contract Risk Management represents the lowest GPI (GPI= 50.5\%) among other groups, and therefore, it could be argued that there should be an urgent need to re-structure this process and initiate an urgent continual improvement program for risk management. The literature revealed a similar low performance of risk management in other countries (Surajbali 2016). Following the performance rating scale, it could be concluded that group performance indicators are good except for risk management.

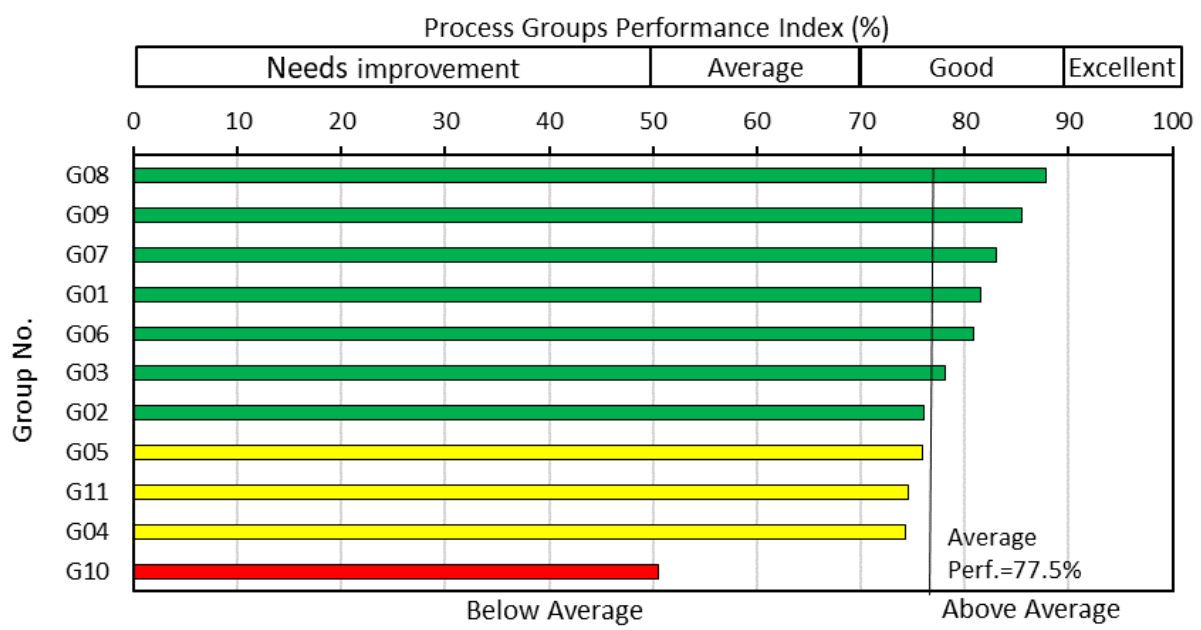

Figure 3: Benchmarking values of the process group 


\section{CONCLUSION}

Based on the authors' established systematic, operational, and multi-dimensional construction Contract Administration Performance Framework (CAPF) and model (CAPM), this study demonstrates the practical implementation of the CAPM for practitioners and researchers to use in calculating CCA Group Performance Indices (GPI) and the overall CCA performance index (CCAPI) for public and private projects of different types and sizes. By using factual data from 13 construction projects in Qatar, the practical implementation of CAPM is demonstrated.

Results from the case study showed that the CAPM implementation has a practical application to identify variations in performance levels among the process groups and project performances, as well. The benchmarking value for the CCAPI $(77.5 \%)$ demonstrates that the level of CCA performance is good. The CCAPI of the public sector $(82.4 \%)$ is remarkably higher than the private sector $(74.5 \%)$. Also, the performance of CCA process groups is good, except risk management, which needs improvement. The CCA performance measurement approach presented in this study can be applied to different construction projects, and the weight of the measures could be changed to cover special projects priorities.

\section{REFERENCES}

AECOM (2016). Middle East Handbook: Property and Construction Handbook, AECOM Middle East, 1-120.

Arcadis (2017). Global construction disputes 2017: The higher stakes, the bigger the risk, pp. $1-29$.

Authority (2018). Qatar economic outlook 2018-2020. Ministry of Development Planning and Statistics. Doha, 1-50.

Awwad, R., Barakat B. \& Menassa C. (2016). Understanding dispute resolution in the Middle East region from perspectives of different stakeholders. Journal of Management in Engineering, 32(6), 05016019.

Bin Zakaria, Z., Binti Ismail S. \& Binti Yusof A. (2013). An overview of comparison between construction contracts in Malaysia: The roles and responsibilities of contract administrator in achieving final account closing success. 2013 International Conference on Education and Educational Technologies Rhodes Island, Greece.

Gitonga, J. M., Nzulwa J. \& Kwena R. (2017). The effect of critical success factors on the completion of public construction projects in Machakos County Kenya. Strategic Journal of Business \& Change Management, 4(3-35): 529-543.

Gunduz, M., Birgonul M. T. \& Ozdemir M. (2018). Development of a safety performance index assessment tool by using a fuzzy structural equation model for construction sites, Automation in Construction, 85: 124-134.

Gunduz, M. \& Elsherbeny H. A. (2019). Operational framework for managing construction contract administration- practitioners' perspective through modified Delphi method. Journal of Construction Engineering and Management (in press).

Harris, E. C. (2013). Global construction disputes: A longer resolution. Global Construction Report. 1: 17.

Jarkas, A. M. \& Mubarak S. A. (2016). Causes of construction change orders in Qatar: con- 
tractors' perspective. International Journal of Project Organisation and Management, 8(3): 275-299.

Patajoki, U. (2013). Towards a successful contractual relationship-public service procurement from a small business perspective. Master, Aalto University.

PWA (2010). Professional services -general conditions of engagement, Public Works Authority, Doha, 1-44.

Statistics (2016). Qatar economic outlook 2016-2018. Ministry of Development Planning and Statistics. Doha, Qatar, 1-37.

Surajbali, R. R. (2016). Determining contract management challenges relating to supply chain management in the Eastern Cape Department of Education, Master of Public Administration, North-West University, Potchefstroom Campus, 1-171. 


\section{APPENDIX A: CONSTRUCTION CONTRACT ADMINISTRATION FRAMEWORK}

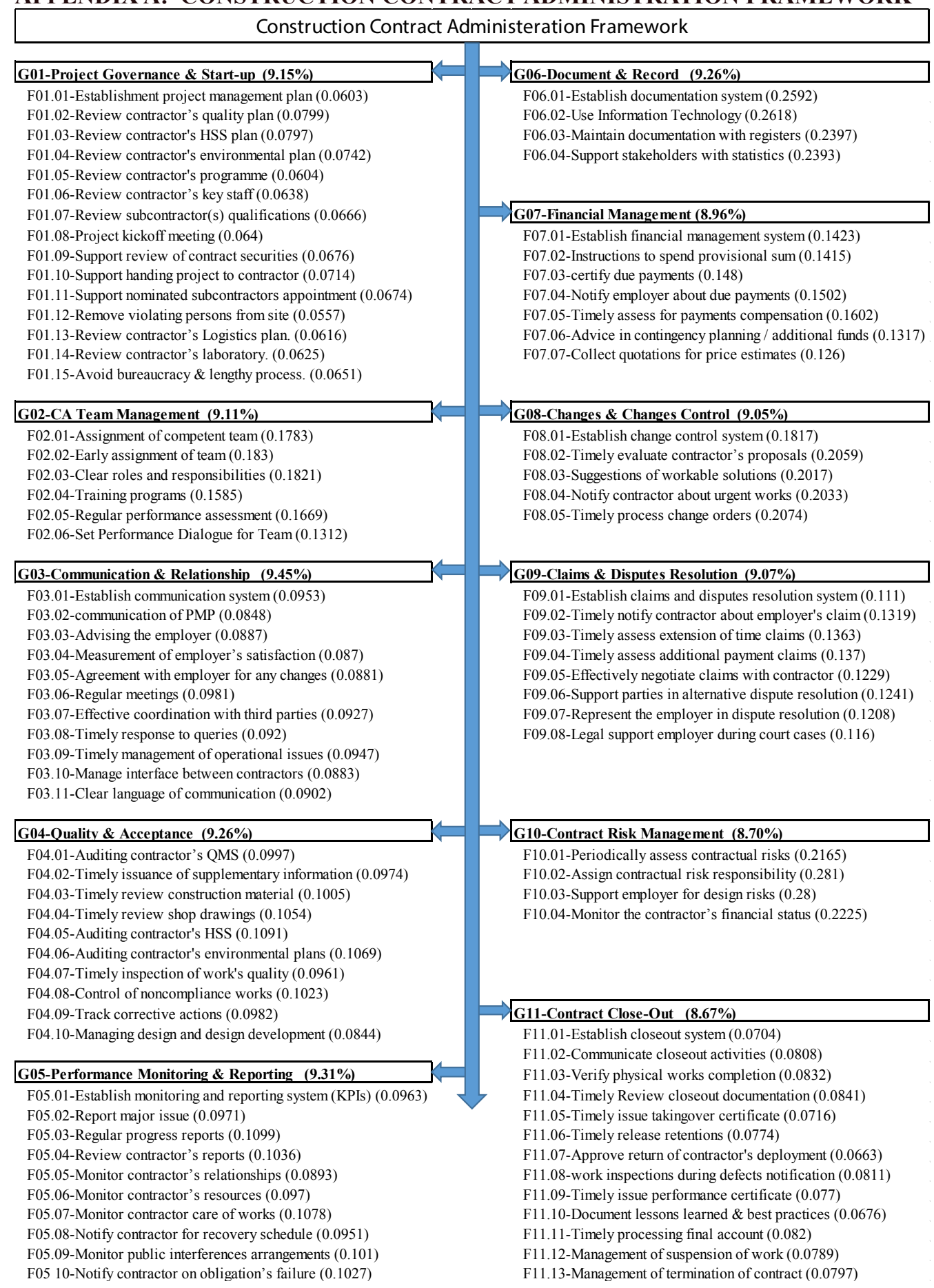

Weights within Group is shown between brackets. 